\title{
The long-term administration of Orai 1 antagonist possesses antitussive, bronchodilatory and anti-inflammatory effects in experimental asthma model
}

\author{
Martina Šutovská1, Michaela Kocmálová ${ }^{1}$, Marian Adamkov², Desanka Výbohová ${ }^{3}$, Pavol \\ Mikolka $^{4}$, Daniela Mokrá ${ }^{4}$, Jozef Hatok ${ }^{5}$, Martina Antošová ${ }^{1}$ and Soňa Fraňová ${ }^{1}$ \\ ${ }^{1}$ Department of Pharmacology, Jessenius Faculty of Medicine, Comenius University, Martin, Slovak Republic \\ ${ }^{2}$ Institute of Histology and Embryology, Jessenius Faculty of Medicine, Comenius University, Martin, Slovak Republic \\ ${ }^{3}$ Institute of Anatomy, Jessenius Faculty of Medicine, Comenius University, Martin, Slovak Republic \\ ${ }^{4}$ Institute of Physiology, Jessenius Faculty of Medicine, Comenius University, Martin, Slovak Republic \\ ${ }^{5}$ Institute of Medical Biochemistry, Jessenius Faculty of Medicine, Comenius University, Martin, Slovak Republic
}

\begin{abstract}
The best-studied store-operated $\mathrm{Ca}^{2+}$ channels (SOCs), $\mathrm{Ca}^{2+}$ release activated $\mathrm{Ca}^{2+}(\mathrm{CRAC})$ channels, are activated by depleting endoplasmic reticulum $\mathrm{Ca}^{2+}$ pool and mediate $\mathrm{Ca}^{2+}$ influx vitally important for $\mathrm{Ca}^{2+}$ restoration and many cellular function. CRAC channels were identified on immune and airway smooth muscle (ASM) cells. Emerging evidence points to its involvement in allergic airways diseases. This article evaluated therapeutic potency of CRAC antagonist in experimental animal model of allergic asthma.

Allergic asthma, induced by repetitive exposure of guinea pigs to ovalbumine, was followed by 14 days therapy by CRAC antagonist (3-fluoropyridine-4-carboxylic acid, FPCA). In vivo changes of specific airways resistance (sRaw) evaluated bronchodilatory effect of FPCA and salbutamol. The method of citric acid-induced cough reflex assessed antitussive activity of FPCA and codeine. The measurement of exhaled NO ( $\mathrm{E}_{\mathrm{NO}}$ ), expression of inducible NO-synthase (iNOS) by RT-PCR and immunohistochemical staining of airways tissue verified anti-inflammatory effect of FPCA. Long-term administration of FPCA resulted in significant cough suppression and bronchodilation, both comparable to the effect of control drugs. FPCA significantly decreased $\mathrm{E}_{\mathrm{NO}}$ and iNOS expression, which together with immunohistochemical analysis validated its anti-inflammatory effect.

Presented data confirmed CRAC channels as a promising target for treatment of respiratory diseases associated with allergic inflammation.
\end{abstract}

Key words: Allergic asthma - Mast cells — Cough reflex - CRAC channels - Nitric oxide

\section{Introduction}

The intracellular sources in endoplasmic/sarcoplasmic reticulum as well as membrane $\mathrm{Ca}^{2+}$ permeable ion channels participate in rise of intracellular calcium $\left(\mathrm{Ca}^{2+}\right)$ in all cells. Except from voltage-operated channels (VOC), playing a significant role in many excitable tissues, membrane $\mathrm{Ca}^{2+}$

Correspondence to: Martina Sutovska, Department of Pharmacology, Jessenius Faculty of Medicine, Comenius University, Sklabinska Street 26, 037 53, Martin, Slovak Republic

E-mail: sutovska@jfmed.uniba.sk permeable ion channels are divided into store-operated (SOCs) and receptor-operated channels (ROCs).

SOCs are activated through a decrease in $\mathrm{Ca}^{2+}$ pool of endoplasmic reticulum. The best-studied SOC is a subtype known as the $\mathrm{Ca}^{2+}$ release-activated $\mathrm{Ca}^{2+}$ (CRAC) channel. CRAC channel was defined electrophysiologically about two decades ago by Hoth and Penner (1992) in mast cells and by Lewis and Cahalan (1989) in T cells. However, its molecular identity remained unknown until 2005, when protein serving as sensor of endoplasmic reticulum $\mathrm{Ca}^{2+}$ depletion (stromal interaction molecule, STIM) was identified (Zhang et al. 2005) followed by discovery of pore-forming subunit, plasma 
membrane channel protein Orai in 2006 (Feske et al. 2006). STIM senses the depletion of $\mathrm{Ca}^{2+}$ from the endoplasmic reticulum, oligomerize, translocate to junctions adjacent to the plasma membrane, organizes the Orai subunit into clusters and open these channel (Hogan et al. 2010). Increasing intracellular $\mathrm{Ca}^{2+}$ leads to dissociation of subunits and inhibits CRAC channel function.

CRAC channels are widely expressed in immune cells and generate local cytoplasmatic $\mathrm{Ca}^{2+}$ signals important for wide spectrum of their activities. Mast cell degranulation and release of mediators from immune cells represents one of the examples of a vitally $\mathrm{Ca}^{2+}$-dependent biological process in non-excitable cells. Mast cells release of $\mathrm{Ca}^{2+}$ from endoplasmic reticulum stores and CRAC-dependent pathway are sufficient to activate $\mathrm{Ca}^{2+}$ influx necessary for degranulation of histamine, serotonin, heparin, neutral proteases as well de novo synthesis of leukotrienes and prostaglandins; and cytokines and chemokines as a key mediators of allergic inflammation (Woolhiser et al. 2004). McNally et al. (2009) indicated that CRAC channels serve also as a major route of $\mathrm{Ca}^{2+}$ entry in lung epithelial cells and their activation leads to (except for NO production) robust increase of transcriptional regulator NFAT (nuclear factor of activated T-cells) and the production of proinflammatory cytokines.

Contraction of airway smooth muscle (ASM) is a key response underlying bronchoconstriction in asthmatic airways and bronchoconstriction plays important role in cough response. According to Widdicombe (2003), rapidly adapting receptors (RARs) should be activated by bronchospasm. Methacholine or histamine, agents used to provoke ASM contraction, are also able to initiate cough reflex. Furthermore, Chung (2005) reported antitussive effect of standard bronchodilatory agents.

Although it has been clear for many years that $\mathrm{Ca}^{2+}$ plays a key role in the contractile response, the mechanisms underlying control of $\mathrm{Ca}^{2+}$ homeostasis have been uncertain. In vascular smooth muscle, VOC are the most important in $\mathrm{Ca}^{2+}$ homeostasis, but the contractile response of ASM is mainly dependent on both release from intracellular stores and influx through nonvoltage-dependent pathways (Brightling and Bradding 2005). Thus, major contractile agonists, such as histamine, will activate $\mathrm{Ca}^{2+}$ signals by rapid release from internal stores followed by a more sustained $\mathrm{Ca}^{2+}$ influx via plasma membrane ROCs and SOCs.

Over the last few decades many mechanisms of communication between intracellular stores and plasma membrane ion channels have been proposed, including the release of diffusional messengers and vesicle fusion, all of which have remained controversial (Clapham 2003). Peel et al. (2006) a short time ago declared a role for STIM1 and potential roles for the three known human Orai homologs in the activation of SOC influx in primary human ASM cells (Peel et al. 2008). These findings supported study by Sutovska et al. (2013). They demonstrated the role of CRAC channels in contraction of ASM both in vivo and in vitro conditions as well as in pathophysiology of experimentally induced allergic asthma in guinea pigs.

This is emerging evidence that the major symptoms of allergic asthma, e.g. the inflammatory reaction, hyperresponsiveness of ASM and pathological cough, are directly or indirectly linked to the activity of CRAC channels. Presented study was focused in the influence of long-term therapy by CRAC antagonist on the main symptoms of asthma using the experimental animal model of allergic airways inflammation and evaluated therapeutic potency of tested agent in the treatment of respiratory diseases causally associated with allergic inflammation of the airways.

\section{Materials and Methods}

All experiments were approved by Institutional Ethics Committee of the Jessenius Faculty of Medicine, Comenius University in Martin, Slovakia, registered in Institutional Review Board/Institutional Ethic Board Office (IRB 00005636), decision No. 611/2010, complied with Slovakian and European Community regulations for the use of laboratory animals and follow the criteria of experimental animal's well fare.

\section{Animals}

Pathogen-free adult male Trik strain guinea pigs, weighing 150-300 g, were obtained by breeding facility Velaz (Prague, Czech Republic) and were housed under controlled conditions in approved animal holding facility. Water and commercial feed were allowed ad libitum. The guinea pigs were free of respiratory airways infections as assessed by the regular health monitoring quality controls. The animals in total number 50 were used in experiments after one-week adapting period and after their adaptation to our experimental conditions. During this period guinea pigs were repetitively placed into the bodyplethysmograph box to achieve 20 min time interval of undisturbed respiration.

\section{Chemicals}

Acetylcholine, histamine, citric acid, chicken ovalbumine, $\mathrm{Al}(\mathrm{OH})_{3}$, codeine, salbutamol and budesonide were purchased from Sigma Aldrich (Lambda Life, Slovakia). 3-fluoropyridine-4-carboxylic acid (FPCA) was obtained from Alfa Aesar (Germany). Budesonide for nebulisation was prepared as suspension in 1\% TWEEN 80 (in $0.9 \%$ saline) according to manufacturer's instruction. CRAC channels antagonist, salbutamol and codeine were dissolved in water for injection and all other above-mentioned drugs in $0.9 \%$ saline. 


\section{Study Design}

The guinea pigs were divided into the following groups, each consisting of 10 animals:

- Negative control - the group of sensitized animals received water for injection in the dose $1 \mathrm{ml} / \mathrm{kg}$ b.w. intraperitoneally (i.p).

- Positive controls - three groups of sensitized guinea pigs received salbutamol (10 mg/kg b.w i.p.), codeine $(10 \mathrm{mg} / \mathrm{kg}$ b.w. perorally) or budesonide $(3 \mathrm{mg} / \mathrm{ml}$ by inhalation for $5 \mathrm{~min}$ ). Salbutamol was used as control drug in ASM reactivity tests, codeine in measurement of cough response and budesonide in measurements of exhaled $\mathrm{NO}\left(\mathrm{E}_{\mathrm{NO}}\right)$ and assessment of iNOS expression.

- Experimental group - one group of animals underwent long-term (14 days) therapy by FPCA in the dose $1.5 \mathrm{mg} /$ $\mathrm{kg}$ b.w. (i.p.). According to Whitten et al. (2011), CRAC antagonist (FPCA) is a representative of agents able suppresses the activity of CRAC channels through interaction with Orai 1 protein. The dose of FPCA for long-term administration was selected from the doses used in acute therapy according to their influence on the defence airway reflexes and occurrence of side effects followed in previous study (Sutovska et al. 2013).

\section{Experimental asthma model}

Sensitization of animals by ovalbumin, previously depicted by Franova et al. (2013), was performed during 21 days. The allergen adsorbed on $\mathrm{Al}(\mathrm{OH})_{3}$ was administered parenterally in the same single dose $(0.5 \mathrm{mg}$ of ovalbumine and $100 \mathrm{mg}$ of $\left.\mathrm{Al}(\mathrm{OH})_{3}\right)$ as follows: at Day 1 i.p. and subcutaneously (s.c.), at Day 3 i.p. and at Day 9 s.c. Inhalation of ovalbumin $\left(10^{-5} \mathrm{~mol} / \mathrm{l}\right)$ was performed at Day 12 , Day 15, Day 18 and Day 20 using double chambered whole bodyplethysmograph box for small laboratory animals (HSE type 855, Hugo Sachs Elektronik, Germany). All tests with sensitized animals were accomplished $24 \mathrm{~h}$ after last allergen provocation.

\section{Evaluation of ASM reactivity, in vivo}

In vivo ASM reactivity was recorded as values of specific airway resistance (sRaw) measured in double chambered bodyplethysmograph box consisting of head and body chambers. The sRaw is proportional to phase difference of pressure changes between both chambers of bodyplethysmograph. Values of sRaw were calculated according to Pennock et al. (1979) and their changes were regarded as indicator of in vivo airways reactivity.

The sRaw values were measured during $1 \mathrm{~min}$ time interval consecutively after exposure to citric acid $(0.3 \mathrm{M})$ and histamine (in concentration $10^{-6} \mathrm{M}$ ). Their intensity prior to administration of salbutamol, negative control drug and FPCA, were considered as baseline ( $\mathrm{N}$ values in graphs). The next ones values were measured 60,120 and $300 \mathrm{~min}$ after last dose of agents applied. The 1 min time interval was between the exposure to bronchoprovocation agent and measurement of sRaw. During this time fresh air was insufflated into the nasal chamber.

\section{Assessment of cough reflex}

The method of citric acid-induced cough used for assessment of cough reflex was previously described in details by Sutovska et al. (2007). We preferred citric acid aerosol in concentration of $0.3 \mathrm{M}$ in saline generated by jet nebulizer (PARI jet nebuliser, Paul Ritzau, Pari-Werk GmbH, Germany, output $5 \mathrm{l} / \mathrm{s}$, particles mass median diameter $1.2 \mu \mathrm{m}$ ) for cough provocation.

The inhalation of citric acid in double chambered bodyplethysmograph lasted $3 \mathrm{~min}$. During this time the number of the coughs was evaluated and counted on the basis of expiratory flow changes interrupting the basic respiratory curve accompanied by a typical cough movement and sound of animals recognized by two independed trained observers.

The cough response was measured prior to any agent's administration (baseline measurement; $\mathrm{N}$ in graphs) and then 60,120 and $300 \mathrm{~min}$ after their last dose applied. The time difference between two measurements correlated with ERS (European respiratory society) guidelines (Morice et al. 2007).

\section{Measurement of $E_{N O}$}

$\mathrm{E}_{\mathrm{NO}}$ levels were measured by chemiluminescence method in animals individually placed into the offline chamber sampling connected with NIOX Flex Offline Start Kit 04-1210-F (Aerocrine AB, Sweden). Guinea pigs breathed NO-free air for $5 \mathrm{~min}$. Subsequently the exhaled gas (flow rate $5 \mathrm{ml} / \mathrm{s}$ ) was analyzed for $7 \mathrm{~s}$. $\mathrm{E}_{\mathrm{NO}}$ levels were expressed in ppb (particle per billion). $\mathrm{E}_{\mathrm{NO}}$ values were measured in negative control group, positive control group treated by budesonide and experimental group before and after sensitization procedure and after long-term therapy.

\section{Method of RT-PCR}

Total RNA from lung homogenate guinea pig samples was isolated using RNeasy ${ }^{\circledast}$ Micro Kit (QIAGEN Group) and cDNA synthesis was conducted using QuantiTect ${ }^{\circledR}$ Reverse Transcription Kit (QIAGEN Group) following the manufacturer's instruction.

Primers for RT-PCR: iNOS primer sequences (forward: GCAGCAGCGGCTTCACA; reverse: ACATCCAAACAG- 
GAGCGTCAT) used for a guinea pig were published previously (Cho et al. 2005; Yamada et al. 2005) and checked for sequence homology against known sequence of Cavia porcellus iNOS, mRNA (NCBI Reference Sequence: NM_ 001172984.1). Hypoxanthine phosphoribosyltransferase (HPRT) was used as reference gene. Primer sequences were published previously, too (Cho et al. 2005). All data were normalized to HPRT mRNA expression of the same sample.

RT-PCR was performed by QuantiTect ${ }^{\circledR}$ SYBR $^{\circledR}$ Green PCR Kit (QIAGEN Group), following the manufacturer's instruction. $1 \mu \mathrm{l}$ of cDNA from reverse transcription was added to $25 \mu \mathrm{l}$ mastermix reaction. Quantitative PCR was performed using the iCycler iQ ${ }^{\otimes} 5$ (Bio-Rad Laboratories, Inc.) for 45 cycles at $95^{\circ} \mathrm{C}$ for $15 \mathrm{~s}$, primer-specific annealing temperature at $60^{\circ} \mathrm{C}$ for $1 \mathrm{~min}$, and $72^{\circ} \mathrm{C}$ for $30 \mathrm{~s}$. The crossing point, or the cycle number at which the fluorescence of the sample exceeded that of the background, was determined by the Bio-Rad iQ5 - Standard Edition Optical System Software 2.0 using the second derivative method. Each cDNA sample was tested in the RT-PCR assay in triplicate.

\section{Immunohistochemical staining}

Immunohistochemical analysis of tracheal and pulmonary samples (size $10 \times 10 \times 5 \mathrm{~mm}$ ) aimed on mast cells infiltration of tissue was based on detection of mast cells tryptase. According to Brown et al. (2007), releasing of tryptase from activated mast cells is significantly CRAC-dependent pathway.

Immunohistochemical staining was done on formalin fixed-paraffin embedded tissue. Each paraffin block was cut into four micrometer sections subjected to stain. For greater adherence of tissue sections to glass slides, we used Flexslides, which were baked in an oven at $59^{\circ} \mathrm{C}$ for two hours. Then, the slides were treated in PT Link system (DAKO). The endogenous peroxidase activity was quenched with $3 \%$ hydrogen peroxide. Immunohistochemical reaction was performed using mouse anti-mast cell tryptase (DAKO, S640, Clone AA1, Kit K 0609 LSAB system) for 20 minutes. The reaction was visualized by incubation with chromogen (3,3'-diaminobenzidine) for 2-3 min and counterstained with Meyers' haematoxylin.

All double blind labelled microscopic slides were assessed by two independent observers from our laboratory (M. A., M. S.). Cases with the discrepancy between observer's results were noticed and after that they were repeatedly assessed by both observers together using dualhead microscope. In every processed specimen, the degree of mast cells infiltration was semiquantitatively determined by manner previously well described by Sutovska et al. 2013 (negative result = degree of infiltration 0 and 1 ; positive result $=$ degree of infiltration 2 and 3$)$.

\section{Statistical analysis}

Except from histological results, all obtained data are shown as means \pm S.E.M. For their statistical analysis, Student's $t$-test was used. The Fisher's exact test was selected to evaluate the immunohistochemical features.

The results with $p<0.05$ and lower were considered as statistically significant and were marked by asterisks in graphs.

\section{Results}

The changes of in vivo ASM reactivity

Long-term treatment of sensitized animals by FPCA resulted in significant decrease of sRaw values regardless to used sort of bronchoprovocation, citric acid or histamine. Citric acid-induced changes of sRaw were similarly influenced by both FPCA as well as salbutamol. According to Fig. 1 it is distinct that histamine-induced airways irritation was

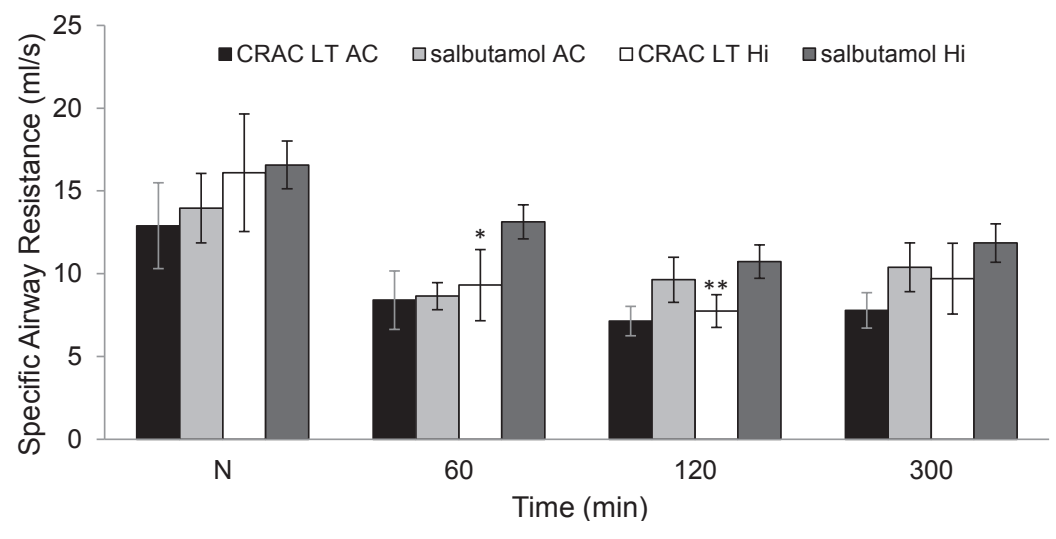

Figure 1. The changes of specific airways resistance $(\mathrm{ml} / \mathrm{s})$ induced by citric acid (AC) and histamine $(\mathrm{Hi})$ recorded in guinea pigs underwent long-term administration of CRAC antagonist (CRAC LT AC, CRAC LT Hi) and control drug salbutamol (salbutamol AC, salbutamol $\mathrm{Hi}$ ). ${ }^{*} p<0.05 ;{ }^{* *} p<0.01$ CRAC LT groups $v s$. salbutamol groups. 
Table 1. The values of specific airways resistance (sRaw) as the response on bronchoconstrictors, citric acid (sRaw AC) and histamine (sRaw Hi), recorded in guinea pigs treated long-term by CRAC antagonist (CRAC LT) and vehicle (OVA 21)

\begin{tabular}{llcccc}
\hline Group & Measurement & sRaw AC $(\mathrm{ml} / \mathrm{s})$ & $p$ & sRaw Hi (ml/s) & $p$ \\
\hline \multirow{3}{*}{ OVA 21 } & Baseline & $4.71 \pm 0.41$ & - & & - \\
& $\mathrm{N}$ & $17.15 \pm 1.9$ & - & $22.26 \pm 0.88$ & - \\
& $60 \mathrm{~min}$ & $14.20 \pm 1.58$ & - & $18.26 \pm 0.59$ & - \\
& $120 \mathrm{~min}$ & $16.7 \pm 1.81$ & - & $19.82 \pm 0.9$ & - \\
& $300 \mathrm{~min}$ & $16.51 \pm 1.03$ & - & $19.64 \pm 1.07$ & - \\
\hline \multirow{2}{*}{ CRAC LT } & Baseline & $2.16 \pm 0.16$ & 0.0005 & - & 0.0699 \\
& $\mathrm{~N}$ & $12.9 \pm 2.59$ & 0.0530 & $16.09 \pm 3.55$ & 0.0007 \\
& 60 min & $8.41 \pm 1.76$ & 0.0110 & $9.31 \pm 2.15$ & 0.0001 \\
\hline
\end{tabular}

The sRaw were measured before any challenge (Baseline) and after that prior to application of FPCA and vehicle (N) and 60, 120 and $300 \mathrm{~min}$ after last doses administered. Data are presented as average \pm S.E.M., statistical significance evaluated using Student's $t$-test, pvs. OVA 21.

suppressed by FPCA more significantly in comparison with classic bronchodilating drug salbutamol.

Baseline sRaw values registered in animals treated by FPCA were significantly lower than those in negative control group. Long-term administration of vehicle alone showed only minor changes of sRaw recorded 60, 120 and $300 \mathrm{~min}$ after last applied dose (Table 1).

\section{The influence of FPCA on citric acid-induced cough}

Long-term administration of CRAC channels antagonist FPCA showed evident cough suppressive effect with prompt onset of the effect and its duration up to last measured time interval. Antitussive activity of FPCA exceeded efficacy of control antitussive drug codeine significantly in measurements 120 min after administration of agents (Fig. 2). The influence of vehicle (water for injection) was tested under the same conditions and resulted only in insignificant changes of cough response.

\section{Levels of exhaled NO and expression of $i N O S$}

Previously, it was demonstrated that allergic inflammation, which was developed in airways, increased $\mathrm{E}_{\mathrm{NO}}$ values significantly (Sutovska et al. 2013). Long-term administration of FPCA as well as control drug budesonide resulted in significant decrease of this approximate parameter of inflammation (Fig. 3). According to the



Figure 2. The changes of coughs number induced by citric acid $(0.3 \mathrm{M})$ recorded in guinea pigs underwent long-term administration of CRAC antagonist (CRAC LT) and compared to codeine (codeine OVA 21) and vehicle alone (OVA 21) tested under the same conditions in sensitized animals. ${ }^{\star} p<0.05$ vs. codeine OVA 21.

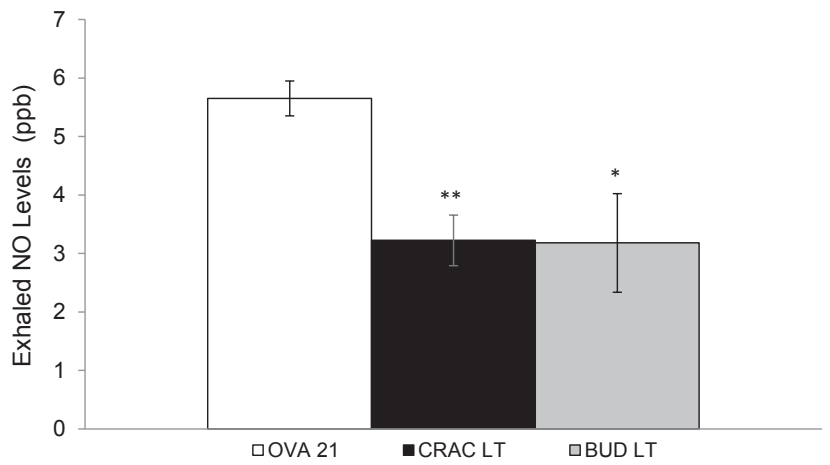

Figure 3. The changes of exhaled NO levels measured in sensitized guinea pigs (OVA 21) and sensitized animals after long-term application of CRAC antagonist (CRAC LT) and budesonide (BUD LT). The levels were registered $60 \mathrm{~min}$ after administration of FPCA and control drugs. ${ }^{\star} p<0.05 ;{ }^{* *} p<0.01 v s$. OVA 21. 


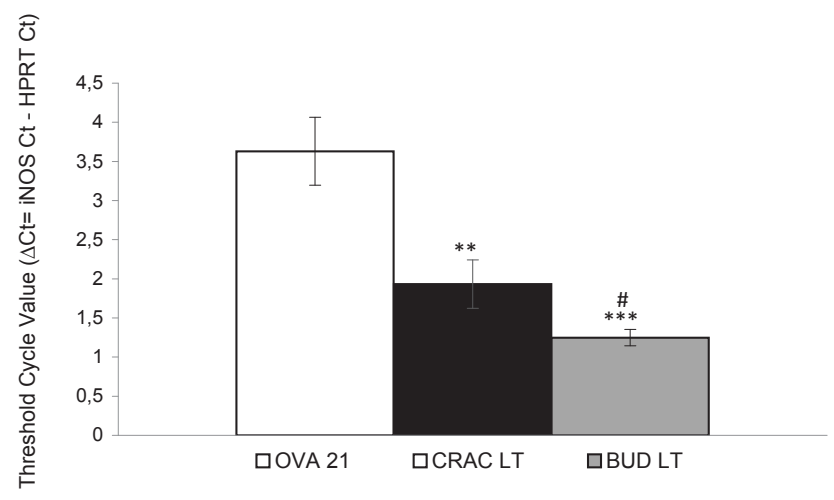

Figure 4. The expression of iNOS in sensitized animals (OVA 21) compared with the groups underwent long-term treatment by CRAC antagonist (CRAC LT) and control drug budesonide (BUD LT). The levels were measured $60 \mathrm{~min}$ after administration of FPCA and control drugs. A threshold cycle $(\Delta \mathrm{Ct})$ values were obtained by subtracting HPRT (hypoxanthine phosphoribosyltransferase) Ct values from respective target gene (iNOS) Ct values. $\# p$ vs. CRAC LT; ${ }^{* *} p<0.01 ;{ }^{* * *} p<0.001$ vs. OVA 21.

RT-PCR findings it is evident that reduced $\mathrm{E}_{\mathrm{NO}}$ could be the result of inhibited iNOS expression (Fig. 4). Furthermore, budesonide depressed iNOS more significantly than CRAC antagonist.

\section{Immunohistochemical analysis}

Manifest tryptase positivity evidenced in tracheal and pulmonary sections of ovalbumin-sensitized guinea pigs (OVA 21) were significantly suppressed in experimental group of animals underwent long-term therapy by FPCA (Table 2). Mast cells infiltration of pulmonary tissue (Fig. 5) was decreased with lower significance than tracheal sections (one-sided Fisher's exact test). These findings, together with results of $\mathrm{E}_{\mathrm{NO}}$ and iNOS expression suggested strong antiinflammatory potency of CRAC antagonist.

\section{Discussion}

Bronchial asthma is complex inflammatory disorder associated with hyperresponsiveness of ASM, pathological cough, airways remodelling, excessive production of mucus and the cellular infiltration consisting of lymphocytes, eosinophils and neutrophils. In many instances, asthma has an allergic component characterized by sensitivity to certain allergens and increased serum levels of antigen specific IgE as well as total IgE (Brown et al. 2007). The role of the mast cell in asthma is of renewed interest due to reports that mast cell numbers are increased within the airway smooth muscle bundles of asthmatic patients. This has led to a re-evaluation of the mast cell as a crucial effectors cell in the pathogenesis of asthma, especially asthma with an allergic basis (Brightling et al. 2002). Mast cell derived mediators lead to leukocyte recruitment, adhesion and activation as well as to $\mathrm{Th}_{2}$ differentiations, which promotes production of allergen-specific IgE by B cells. Ultimately, mast cells initiate a process resulting in typical cellular pattern of allergic airways inflammation. Therefore, immunohistochemical analysis of tissue samples isolated from animals, which underwent sensitization procedure by allergen, was pointed to mast cells infiltration of tracheal and pulmonary section. Significant increase of mast cells evidenced by tryptase positivity in respiratory tissue of ovalbumin-sensitized animals confirmed clinical findings mentioned previously and supported the essential role of these cells in development of allergic asthma. Statistically significant decrease of tryptase positivity on long-term administration of CRAC antagonist FPCA indicated on its therapeutic potency.

Except from crucial role in development of allergic inflammation, the location of mast cells within the ASM is believed to facilitate hyperresponsiveness through localized mediator release and/or direct cell-to-cell contact (Begueret et al. 2007). Many mast cell mediators such as histamine, tryptase, IL-4, IL-13, $\mathrm{PGD}_{2}$ and $\mathrm{LTC}_{4}$, will

Table 2. The number of pulmonary and tracheal sections with positive and negative mast cells infiltration in unsensitized control group, ovalbumin-sensitized animals and experimental group of sensitized animals underwent long-term therapy by CRAC channels antagonist

\begin{tabular}{lcccccccc}
\hline & \multicolumn{4}{c}{ Pulmonary sections } & \multicolumn{3}{c}{ Tracheal sections } \\
\cline { 2 - 9 } & negative & positive & number & $p$ & negative & positive & number & $p$ \\
\hline NCG & 9 & 0 & 9 & $\begin{array}{c}1.00 \\
\text { (one sided 0.5) }\end{array}$ & 9 & 1 & 10 & $\begin{array}{c}\text { (one sided 0.5) } \\
0.0001\end{array}$ \\
OVA 21 & 2 & 4 & 6 & $\begin{array}{c}0.089 \\
\text { (one-sided 0.047) }\end{array}$ & 0 & 6 & 6 & (one-sided 0.0001) \\
CRAC LT & 8 & 1 & 9 & - & 10 & 0 & 10 & - \\
\hline
\end{tabular}

Statistical significance evaluated by Fisher's exact test, $p$ vs. CRAC LT. NCG, negative unsensitized control group; OVA 21,senzitized untreated guinea pigs; CRAC LT, experimental group underwent long-term therapy by FPCA. 
A

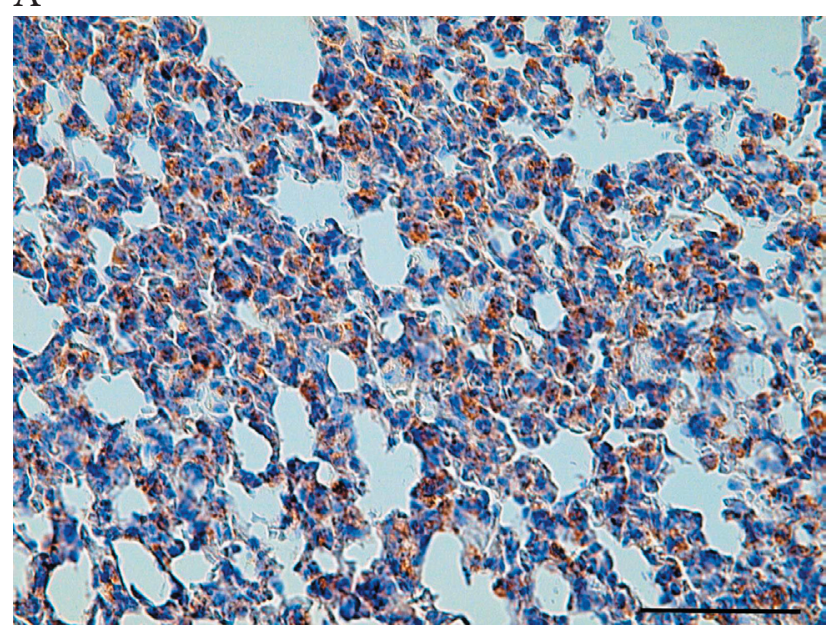

B

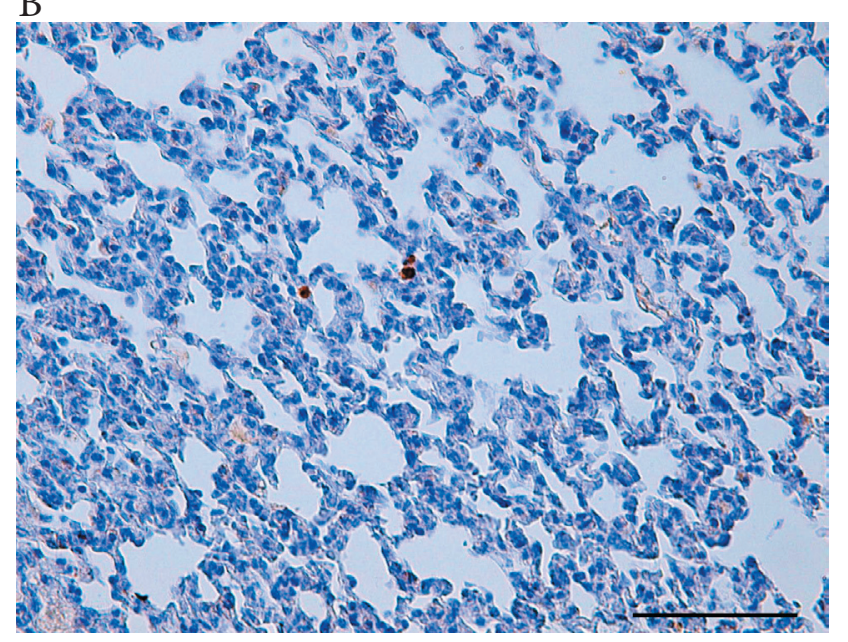

Figure 5. Immunohistochemical staining focused on mast cells infiltration verified by evidence of anti-mast cells tryptase in pulmonary tissue. A. Pronounced diffuse infiltration by mast cells of lung parenchyma isolated from sensitized control guinea pig (scale bar represents $100 \mu \mathrm{m}$ ). B. Minor focal mast cells infiltration of lung tissue obtained from sensitized animal underwent long-term therapy by CRAC channels antagonist FPCA (scale bar represents $200 \mu \mathrm{m})$.

induce contraction of ASM cells, e.g. tryptase causes bronchial hyperresponsiveness in dogs and in isolated human bronchi stimulates cytokine production from ASM (Berger et al. 2002). Moreover, Peel et al. $(2006,2008)$ evidenced existence of CRAC channels on human ASM cells and our previous study confirmed their participation on ASM contractility using both in vivo and in vitro experimental methods (Sutovska et al. 2013). This correlated to the results of ASM reactivity in vivo conditions, followed in presented study. FPCA decreased both baseline and sRaw significantly recorded as a response to $\mathrm{AC}$ and histamine. Furthermore,
sRaw values induced by histamine were inhibited more significantly after long-term treatment by FPCA than after control drug salbutamol. sRaw is proportional to phase difference between nasal and thoracic respiratory airflow. Plethysmograph as a non-invasive technique is commonly used for evaluation of bronchoactive substances effect (Tohda et al. 2000).

Wide spectrum of cells involved in allergic inflammation produce mediators, e.g. prostaglandins or histamine, enhanced also the sensitivity of bronchopulmonary $\mathrm{C}$ fibres and RARs, which presumably heightens the defence function during the airways inflammation and results in pathological cough (Pecova et al. 2007). Furthermore, increased ASM reactivity should also contribute on accented cough response on tussive stimuli, even bronchoconstriction itself should induce cough reflex (Widdicombe 2003). The administration of FPCA showed significant antitussive activity as a result of suppressed CRAC channels activity localized on ASM cells and immune cells.

Many types of cells participated in allergic inflammation directly or indirectly synthesize NO. These comprise especially epithelial cells, fibroblasts, chondrocytes, monocytes/ macrophages, antigen presenting cells, natural killer (NK) cells, eosinophils and mast cells. In these cells a combination of cytokines (TNF, IL-1 $1 \beta$ and IFN- $\gamma$ ) induces iNOS expression and this response is inhibited by glucocorticoids. Glucocorticoids inhibit also IL-4 and IL-13. NO produced by iNOS may exacerbate asthma by inhibiting helper T lymphocyte $\left(\mathrm{Th}_{1}\right)$ and enhancing $\mathrm{Th}_{2}$ responses (Coleman 2002). Nitric oxide plays diverse roles in physiological and pathological processes. During human inflammatory diseases, the best documented example being asthma, $\mathrm{NO}$ is generated at relatively high and sustained levels by iNOS and can readily be detected in the exhaled breath of asthmatics (Kharitonov 2004). Measuring of exhaled NO can therefore be viewed as approximate, non-invasive, though indirect, means of detecting inflammation in the respiratory tract. For that purposes we used adapted $\mathrm{E}_{\mathrm{NO}}$ method to evaluate intensity of allergic airways inflammation in sensitized and treated animals. We observed significant increase of $E_{N O}$ in ovalbumin-sensitized guinea pigs followed by decrease on long-term administration of FPCA and control drug budesonide, both as the result of inhibited expression of iNOS levels evidenced by RT-PCR.

In conclusion, we can summarize that long-term administration of FPCA revealed significant antitussive, bronchodilatory and anti-inflammatory effects in experimental model of allergic asthma. According to these findings, CRAC channels represents very rational target for future antiasthmatic drugs.

Acknowledgements. Presented work was supported by the project "Centre of Experimental and Clinical Respirology II" co-financed 
from EC sources, Grant of Agency for Science (VEGA) No 1/0020/ 11 and 1/0062/11 and Comenius University Grant 213/2012.

The authors declare none conflicts of interest in relation to this article.

\section{References}

Begueret H., Berger P., Vernejoux J. M., Dubuisson L., Marthan R., Tunon-de-Lara J. M. (2007): Inflammation of bronchial smooth muscle in allergic asthma. Thorax 62, 8-15 http://dx.doi.org/10.1136/thx.2006.062141

Berger P., N`Guyen C., Buckley M., Scotto-Gomez E., Marthan R., Tunon-de-Lara J. M. (2002): Passive sensitization of human airways induces mast cell degranulation and release of tryptase. Allergy 57, 592-599 http://dx.doi.org/10.1034/j.1398-9995.2002.203545.x

Brightling C. E., Bradding P., Symon F. A., Holgate S. T., Wardlaw A. J., Pavord I. D. (2002): Mast-cell infiltration of airway smooth muscle in asthma. N. Engl. J. Med. 346, 1699-1705 http://dx.doi.org/10.1056/NEJMoa012705

Brightling C. E., Bradding P. (2005): The re-emergence of the mast cell as a pivotal cell in asthma pathogenesis. Curr. Allergy Asthma Rep. 5, 130-135 http://dx.doi.org/10.1007/s11882-005-0086-9

Brown J. M., Wilson T. M., Metcalfe D. D. (2007): The mast cell and allergic diseases: role in pathogenesis and implications for therapy. Clin. Exp. Allergy 38, 4-18

Cho H., Lasco T. M., Allen S. S., Yoshimura T., MsMurray D. N (2005): Recombinant guinea pig tumour necrosis factor alpha stimulates the expression of interleukin-12 and the inhibition of Mycobacterium tuberculosis growth in macrophages. Infect. Immun. 73, 1367-1376 http://dx.doi.org/10.1128/IAI.73.3.1367-1376.2005

Chung K. F. (2005): Drugs to suppress cough. Expert Opin. Investig. Drugs 14, 19-27 http://dx.doi.org/10.1517/13543784.14.1.19

Clapham D. E. (2003): TRP channels as cellular sensors. Nature 426, 517-524 http://dx.doi.org/10.1038/nature02196

Coleman J. W. (2002): Nitric oxide: a regulator of mast cell activation and mast cell-mediated inflammation. Clin. Exp. Immunol. 129, $4-10$ http://dx.doi.org/10.1046/j.1365-2249.2002.01918.x

Feske S., Gwack Y., Prakriya M., Srikanth S., Puppel S. H., Tanasa B., Hogan P. G., Lewis R. S., Daly M., Rao A. (2006): A mutation in Orail causes immune deficiency by abrogating CRAC channel function. Nature 441, 179-185 http://dx.doi.org/10.1038/nature04702

Franova S., Joskova M., Sadlonova V., Pavelcikova D., Mesarosova L., Novakova E., Sutovska M. (2013): Experimental model of allergic asthma. Adv. Exp. Med. Biol. 756, 49-55 http://dx.doi.org/10.1007/978-94-007-4549-0_7

Hogan P. G., Lewis R. S., Rao A. (2010): Molecular basis of calcium signalling in lymphocytes: STIM and ORAI. Annu. Rev. Immunol. 28, 491-533 http://dx.doi.org/10.1146/annurev.immunol.021908.132550
Hoth M., Penner R. (1992): Depletion of intracellular calcium stores activates a calcium current in mast cells. Nature 355, 353-356 http://dx.doi.org/10.1038/355353a0

Lewis R. S., Calahan M. D. (1989): Mitogen-induced oscillations of cytosolic $\mathrm{Ca} 2+$ and transmembrane $\mathrm{Ca} 2+$ current in human leukemic T cells. Cell Regul. 1, 99-112

Kharitonov S. A. (2004): Exhaled markers of inflammatory lung diseases: ready for routine monitoring? Swiss Med. Wkly. 134, 175-192

McNally B., Yamashita M, Engh A. E., Prakriya M. (2009): Structural determinants of ion permeation in CRAC channels. Proc. Natl. Acad. Sci. U.S.A. 106, 22516-22521 http://dx.doi.org/10.1073/pnas.0909574106

Morice A. H., Fontana G. A., Belvisi M. G., Birring S. S., Chung K. F., Dicpinigaitis P. V., Kastelik J. A., McGarvey L. P., Smith J. A., Tatar M., Widdicombe J. (2007): ERS guidelines on the assessment of cough. Eur. Respir. J. 29, 1256-1276 http://dx.doi.org/10.1183/09031936.00101006

Pecova R., Javorkova N., Kudlicka J., Tatar M. (2007): Tussigenic agents in the measurement of cough reflex sensitivity. J. Physiol. Pharmacol. 58 (Suppl. 5), 531-538

Peel S. E., Liu B., Hall I. P. (2006): A key role for STIM1 in store operated calcium channel activation in airway smooth muscle. Respir. Res. 7, 119 http://dx.doi.org/10.1186/1465-9921-7-119

Peel S. E., Liu B., Hall I. P. (2008): ORAI and store-operated calcium influx in human airway smooth muscle cells. Am. J. Respir. Cell Mol. Biol. 38, 744-749 http://dx.doi.org/10.1165/rcmb.2007-0395OC

Pennock B. E., Cox C. P., Rogers R. M., Cain W. A., Wells J. H. (1979): A noninvasive technique for measurement of changes in specific airway resistance. J. Appl. Physiol. 46, 399-406

Sutovska M., Nosalova G., Franova S. (2007): The role of potassium ion channels in cough and other reflexes of the airways. J. Physiol. Pharmacol. 58, 673-683

Sutovska M., Adamkov M., Kocmalova M., Mesarosova L., Oravec M., Franova S. (2013): CRAC Ion Channels and Airway Defence Reflexes in Experimental Allergic Inflammation. Adv. Exp. Med. Biol. 756, 39-48 http://dx.doi.org/10.1007/978-94-007-4549-0_6

Tohda Y., Muraki M., Ywanaga T., Haraguchi R., Fukuoka M., Nakajima S. (2000): Dual-phase response model for bronchial asthma. Allergy Asthma Proc. 21, 79-84 http://dx.doi.org/10.2500/108854100778250851

Widdicombe J. G. (2003): Overview of neural pathways in allergy and asthma. Pulm. Pharmacol. Ther. 16, 23-30 http://dx.doi.org/10.1016/S1094-5539(02)00178-5

Whitten J. P., Pei J., Cao J., Wang Z., Rogers E., Dyck B., Grey J. (2011): Compounds that modulate intracellular calcium. US patent No. WO/2011/139765

Woolhiser M. R., Brockow K., Metcalfe D. D. (2004): Activation of human mast cells by aggregated IgG through Fc gamma RI: additive effects of C3a. Clin. Immunol. 110, 172-180 http://dx.doi.org/10.1016/j.clim.2003.11.007

Yamada H., Udagawa T., Mizuno S., Hiramatsu K., Suguwara I. (2005): Newly designed primer sets available for evaluating 
various cytokines and iNOS mRNA expression in guinea pig lung tissues by RT-PCR. Exp. Anim. 54, 163-172

http://dx.doi.org/10.1538/expanim.54.163

Zhang S. L., Yu Y., Roos J., Kozak J. A., Deerinck T. J., Ellisman M. H., Stauderman K. A., Calahan M. D. (2005): STIM1 is a Ca2+ sensor that activates CRAC channels and migrates from the $\mathrm{Ca} 2+$ store to the plasma membrane. Nature 437, 902-905

http://dx.doi.org/10.1038/nature04147

Received: October 12, 2012

Final version accepted: November 29, 2012 